\title{
Reseña bibliográfica: Caula, E. (2014). Mercaderes de mar y tierra. Negocios, familia y poder de los vascos en el Río de la Plata. Rosario: FHUYMAR ediciones. 288 pp.
}

Palabras clave: Familia - Negocios - Monarquía Hispánica - Vascos - Redes Sociales

Keywords: Family - Business - Hispanic Monarchy - Basques - Social Networks

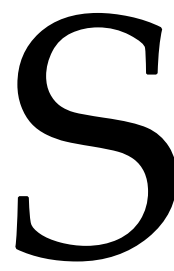
e trata de un libro que condensa la investigación de tesis doctoral de Elsa Caula, Profesora y Licenciada en Historia por la Universidad Nacional de Rosario y Doctora por la Universidad del País Vasco. Su objeto es el vínculo entre familia, negocios y poder a finales del siglo XVIII, cuestión analizada a través de las trayectorias de una serie de familias vascas que emprenderán actividades de amplio alcance territorial. Para el análisis de ese vínculo, Caula apela a un concepto fundamental, el de Casa, base esencial de la organización económica, social y política de la sociedad de Antiguo Régimen (p. 15), entendida como empresa mercantil, y no solo como unidad doméstica. Noción fundamental, en el sentido dado a la expresión por Norbert Elías, como un espacio de intersección entre el gran negocio y la acción política de los agentes de la monarquía (p. 16). La Casa es el observatorio privilegiado para llevar a cabo el seguimiento de las carreras y actividades de los mercaderes, a través del mar y de la tierra. De este modo, la noción de configuración de Elías resulta de vital importancia, porque se trata de hombres y mujeres insertos en sistema relacionales que les permiten actuar y ampliar su margen de maniobra en una sociedad de Antiguo Régimen donde la construcción y el reforzamiento de los vínculos de distinto orden son una herramienta fundamental. La inserción en los espacios de poder locales merced a la posición económica alcanzada, o el caso de los que llegados como funcionarios se incorporan a las redes de comercio asentadas en Buenos Aires, lo ponen de manifiesto. No se pueden entender las acciones y decisiones de los vasco-navarros como comportamientos aislados, dado que las trayectorias observadas, permiten elucidar pautas similares de actuación. La hipótesis central es que los comerciantes oriundos del norte peninsular lograron adaptarse a la experiencia abierta por la Revolución de mayo de 1810, porque previamente habían atravesado circunstancias oscilantes para la ejecución de sus empresas debido al debilitamiento de la Monarquía Hispánica, fuertemente acentuado en el último cuarto del siglo XVIII. Se encuentran presentes en el análisis enfoques provenientes de la historia de la familia y de las migraciones, así como de la historia económica y política. Con ello, la posibilidad de estudiar un mismo objeto de estudio a través de diferentes temáticas contribuye a la conformación de un amplio panorama del período comprendido entre el último tercio del siglo XVIII y el inmediatamente posterior al estallido del proceso 
revolucionario. Como reza el subtítulo del libro, los negocios, la familia y el poder de los vascos son abordados en un contexto general de tensiones en el sistema de alianzas políticas, cuyo desenlace en nuestro continente es el proceso independentista. En ese marco, se inscribe la trayectoria de los protagonistas de esta historia.

El capítulo primero presenta un panorama de ámbito territorial en el que tiene lugar el accionar de los comerciantes oriundos del norte peninsular. Comienza ponderando la escala imperial, tomando en consideración el funcionamiento del régimen colonial bajo el sistema de flotas y galeones, el monopolio de puerto único y los problemas que significaron tales disposiciones en la práctica para mantener un control estricto sobre el comercio con los dominios americanos y al interior de estos. El Cerro Rico de Potosí tiene un rol fundamental en la dinámica económica regional, porque pone en contacto a los distintos espacios del territorio colonial ubicados al sur del Alto Perú, merced a la actividad mercantil, que permitía la colocación de los excedentes de las producciones comarcales en otros mercados regionales y la posibilidad de insertar en aquellos espacios, distintos bienes importados de la península, "los efectos de Castilla" y del resto de Europa, así como del ingreso activo de esclavos. Estos intercambios eran realizados por el actor medular de esta economía: el gran comerciante, que operaba a través de su red de agentes (p. 40). En esta dinámica económica, Buenos Aires juega un papel relevante. Primero como ciudad situada al margen del virreinato del Perú, pero cuya ubicación estratégica le confería un valor significativo en el comercio de contrabando, y luego como capital del virreinato del Río de la Plata. El Reglamento y Aranceles Reales para el Comercio Libre de España a Indias (1778) consolida la tendencia a flexibilizar el comercio entre la península y las colonias, reconociendo una mayor cantidad de puertos habilitados para comerciar a ambas márgenes del océano. Caula señala algunos movimientos expansivos que testimonian la trascendencia que va adquiriendo la ciudad de Buenos Aires en el período de entre siglos: el desarrollo demográfico, debido a la constante entrada de esclavos y la emigración proveniente de otras regiones del espacio interior que, junto a la llegada de los funcionarios y comerciantes peninsulares, impulsan profundas transformaciones en el ejido urbano, las obras para mejorar la navegación fluvial, como así también la intensidad de los intercambios mercantiles.

Señalados estos atributos materiales e institucionales de la ciudad, se comprende la llegada de aquellos importantes comerciantes, en su mayoría originarios de las provincias vasco-navarras, cuyos antecedentes profesionales estaban ligados a la actividad mercantil en sus comarcas de origen y en Cádiz, y que al instalarse en las márgenes del Río de la Plata lo hacen insertándose en el comercio interregional, a veces en función de su unión en matrimonio con las hijas de familias acomodadas de comerciantes previamente instalados en la región. De este modo, el libro señala en su comienzo cuál es el espacio sobre el que operan los protagonistas que dan título a la obra, los mercaderes, que, con sus compañías de comercio y sus correspondientes agentes y representantes en los diversos centros ubicados entre el Río de la Plata y el Alto Perú, atraviesan tanto el mar 
como la tierra, poniendo en contacto los distintos territorios que constituyeron a la Monarquía Hispánica.

El capítulo dos se centra en la integración de los vasco-navarros a la sociedad rioplatense y sus estrategias para asentarse en el comercio imperial, fuente de su prosperidad. El punto de partida es la consideración de este fenómeno migratorio en un proceso más amplio (el de las Reformas Borbónicas) a lo largo del siglo XVIII, tendiente a centralizar el control sobre la administración y a favorecer el comercio, en el cual fueron ganando espacios y preeminencia hombres provenientes de las regiones del norte de la península ibérica.

Los intercambios mercantiles que atravesaban el vasto territorio incorporado a la jurisdicción virreinal estaban asociados a un dinámico conjunto de redes sociales, integradas en su mayoría por los comerciantes y agentes vasco-navarros, ligados entre sí por distintos vínculos que muchas veces respondían a relaciones previas originadas en la península o, más específicamente, en la aldea de origen, y que se reproducían en América.

La autora identifica en clave microhistórica el origen de los hermanos Beláustegui; Joseph, el mayor que emigró a Cádiz y desde allí promovió a su hermano Francisco, que fue quien arribó al Río de la Plata. Para ello, Caula trabaja con archivos alojados en el País Vasco al fin de reconstruir sus trayectorias y dar cuenta de su temprana vinculación con el comercio peninsular e imperial. El puerto de Buenos Aires juega el papel de punto de entrada y salida de mercancías y de moneda. En virtud de ello y del estatus ganado por la ciudad como capital del virreinato, será el lugar de residencia de muchos mercaderes vasco-navarros, ora por su experiencia en el ámbito del comercio en la península, ora por su desempeño en la burocracia regia y posterior colocación en la sociedad porteña mediante el matrimonio con las hijas de comerciantes anteriormente establecidos. Este comportamiento es puesto de manifiesto por Caula al analizar la conformación del clan Basavilbaso, Azcuénaga y Santa Coloma, compuesto por familias dedicadas al comercio a escala imperial. Se trata de un ejemplo de la importancia que tenían las relaciones de parentesco, entendidas como forma cultural de construir relaciones a partir de la lógica de la solidaridad y de la reciprocidad (p. 40). La minuciosa reconstrucción de las nupcias contraídas por parte de los principales representantes de estas familias en el Río de la Plata es esclarecedora al respecto. Es posible hablar entonces de la existencia de una política familiar de colocación consciente y estable de los miembros de la parentela en los negocios mercantiles y financieros y en las carreras administrativas militares y eclesiásticas a las que sus relaciones les facilitaban el acceso privilegiado (p. 79). Así se comprende la importancia del matrimonio como estrategia económica y social, dado el capital relacional y simbólico incorporado al grupo familiar gracias a la concreción de una unión favorable para las familias de los contrayentes.

El capítulo tercero trata sobre los comerciantes incorporados a la sociedad porteña, quienes junto a los funcionarios de la administración virreinal constituían la élite urbana. Por lo tanto, resaltaban su destacada posición en el entramado social a través de un conjunto de prácticas que señalan una sociabilidad restringida, en la que se establecían las 
relaciones que acentuaban el estatus adquirido. Las reuniones sociales que vinculaban a los miembros de la élite tenían lugar en el espacio interior de la casa, donde las mujeres eran figuras centrales en la organización de las tertulias, en las que regían códigos de pertenencia que bien percibían los concurrentes. Otras manifestaciones de la sociabilidad virreinal porteña se daban en los espacios públicos, en la proclamación de exequias reales o en la celebración del Te Deum, en la concurrencia de las distintas cofradías durante Semana Santa, como así también en las festividades en honor a San Martín de Tours, santo patrono de los comerciantes. Se percibe de este modo la presencia de la religión como un elemento constitutivo de la sociabilidad de éstos miembros de la élite urbana. Contribuciones a la caridad y los apoyos a la construcción de templos dan cuenta de ello. Los límites de pertenencia a uno $\mathrm{u}$ otro sector de la élite muchas veces se difuminan al observarse la participación de muchos de estos grandes comerciantes en el gobierno de la ciudad, ya sea ejerciendo cargos en el cabildo o en el Consulado de Comercio, su presencia no se circunscribía a la actividad mercantil y al patrocinio religioso.

El otro tema abordado es el funcionamiento de la Casa como empresa mercantil, nuevamente tomando el ejemplo de Francisco de Beláustegui y la red de agentes que constituían parte de sus empresas. Vemos a su hermano desde Cádiz comandando los intercambios entre la península y los dominios americanos, a uno de sus hijos tomando parte en los negocios en Buenos Aires, a uno de sus sobrinos asentado en Montevideo surcando los ríos, viajando en frágiles pero veloces zumacas desde Paraguay a Santa Fe o Buenos Aires, intercambiando yerba mate, sebo y cueros. También a los agentes y apoderados presentes en el bajo Perú y Chile, articulando la exportación de cascarilla y cacao, dando forma a una red mercantil de amplio alcance, que sobrepasaba las distancias terrestres y oceánicas.

El cuarto capítulo pone el foco sobre dos familias prominentes del período en cuestión: por un lado, se analiza nuevamente a la familia Beláustegui en la ciudad de Buenos Aires, de la que Caula se sirve para brindar una aproximación a la casa como espacio de residencia y a su orden de jerarquía interno. La unidad doméstica es la clave aquí para situar al lector en la casa entendida como el lugar de residencia, el espacio físico concreto habitado por el rico comerciante vasco y su familia nuclear, parientes de distinto grado de proximidad, agregados y también el infaltable personal de servicios de origen africano, en situación de esclavitud. Ello habilita a imaginar la convivencia cotidiana en una rica casa colonial del virreinato a fines del siglo XVIII y comienzos del XIX, la distribución de sus espacios y los residentes llevando a cabo distintas tareas en función de sus oficios y su posición en el conjunto de intereses de la empresa familiar. Por otro lado, para dar un panorama del régimen de gobierno de ese orden familiar patriarcal, se toma a la familia de José de Echevarría, uno de los más ricos mercaderes de Buenos Aires a fines del siglo XVIII, y a una particular situación que nos permite observar las tensiones que podían darse al interior de la Casa, el sistema de valores imperante.

Gracias a la conservación del archivo privado de la familia Echeverría en el Museo Histórico Provincial de Rosario y de los expedientes de los tribunales civiles por parte del 
Archivo General de la Nación y el Archivo Provincial de La Plata, Caula puede reconstruir la compleja trama que siguió a la decisión de contraer matrimonio de dos personas que estaban directamente sujetas a la tutela del pater familias. Se trata de su hija, María Antonina, y de su sobrino, Vicente Anastasio, quien vivía en la residencia familiar desde muy chico y que había sido incorporado a la familia nuclear como un hijo más. El agravante estaba en el desacato a la decisión del pater familias, que había comprometido su palabra a otro rico comerciante peninsular, a quien pretendía casar con su hija. Partiendo de conflicto semejante, Caula reconstruye el camino que siguió la disputa, que rompió el espacio íntimo de la familia y adquirió estado público. El pleito es magistralmente reconstruido en el curso del capítulo, por lo que es posible inferir también la presencia de la escala imperial como una clave de lectura: el litigio si bien tuvo origen en Buenos Aires, alcanzó repercusiones en otras ciudades americanas e involucró a las máximas autoridades estatales y eclesiásticas, locales y metropolitanas (p. 176). El paso por distintas instancias evidencia la complejidad del asunto, las redes de influencia actuando para trabar la resolución del conflicto, los mecanismos de apelación de los pleiteantes, los tribunales regios y eclesiásticos de Charcas y Buenos Aires para finalmente terminar recayendo en la máxima autoridad en Roma. En suma, el relato toma por momentos un tono novelesco al verse involucradas las sensibilidades de los protagonistas, sus sentimientos y el sistema de valores contra el que debían actuar para cumplir su objetivo.

El último capítulo está dedicado a los mercaderes en tiempos de guerra. Extendiendo la periodización al último tercio del siglo XVIII, teniendo en cuenta los conflictos de orden internacional en los que se ve involucrada la Monarquía Hispánica y los efectos que éstos tuvieron sobre las compañías comerciales. No obstante, lejos de significar una desestructuración perjudicial, las Casas de comercio asentadas en el Río de la Plata, supieron sacar provecho de las circunstancias. Los cambios en el sistema de alianzas abrieron la posibilidad a alcanzar nuevas rutas hasta entonces legalmente vedadas. Las reformas del orden económico implementadas por los Borbones alentaron los intercambios con otros puertos de la geografía colonial, pero, conforme iniciaba el siglo XIX, la liberalización se extendió al comercio con dominios portugueses y, en el caso de la Casa de Álzaga, por ejemplo, permitieron entablar negociaciones con la Liga de las Ciudades Hanseáticas.

En lo que respecta al período revolucionario, encontraremos una interesante nómina de los comerciantes presentes en el cabildo abierto del 22 de mayo de 1810, en el que se votó la destitución de virrey. De un total de 59, 26 se pronunciaron por su continuidad. Esta postura se corresponde con su posicionamiento en el orden colonial, por lo que no es de extrañar que, ante el avance del proceso revolucionario, sufrieran un conjunto de presiones y de imposiciones -entre las que destacan las económicas-, en virtud de su riqueza, pero fundamentalmente en calidad de sospechosos. Los destierros y el exilio así lo señalan: una vez más, Elsa Caula trae a escena a Francisco de Beláustegui, quien será desterrado a la campaña, de donde luego parte a Montevideo hasta que esta deja de ser 
bastión de los realistas y desde donde retorna nuevamente a Buenos Aires, donde sufre un intento de asesinato. Por ello, decide exiliarse en Río de Janeiro, ciudad que, desde la llegada de la corte portuguesa -donde se encuentra nada más y nada menos que la hermana del rey español depuesto, la infanta Carlota Joaquina-, se convierte en baluarte de aquellos que se oponían a la desvinculación con España. Esta trayectoria también es ilustrativa de la participación de la mujer en el marco de la revolución. Su esposa, Melchora Rodríguez, hará las veces de jefa de familia, deliberando con el apoderado general de la Casa sobre los intereses familiares y la seguridad de los detenidos acusados por el orden revolucionario. También la veremo apelando a las contribuciones forzosas impuestas sobre su marido y demás familiares, para así adquirir una posición de mediación que devela una compleja trama de vínculos entre personas con disímiles posiciones políticas.

El capítulo también se centra en las dificultades técnicas que supuso la coyuntura al momento de emprender una expedición comercial. Se analizan detenidamente las demoras en la llegada de la correspondencia, lo que afectaba a un elemento fundamental como lo era la información. A ello se debe sumar la problemática del registro de la embarcación debido a la licencia con la cual debía navegar, el pabellón que debía izar y las persecuciones a las que podía exponerse. El ejemplo está en el tortuoso recorrido de una expedición desde Montevideo, llevada a cabo por los Beláustegui con rumbo a Europa que demoró más de lo esperado por las contingencias mencionadas.

En síntesis, estamos ante una obra que dialoga con algunos clásicos de la historiografía argentina, al considerar a los actores de la élite rioplatense en el tránsito del orden colonial a la independencia y al abordar los intercambios mercantiles en el virreinato, cuya desestructuración será crucial a partir de 1810. Aportes por demás interesantes son las chances de ampliación de escala que ofrece el tratamiento de la unidad comercial/familiar constituida por la Casa, lo que la convierte en una herramienta de análisis para la consideración de problemas más generales, la interacción de las escalas imperial e interimperial y el acento puesto sobre las incertidumbres del ocaso de un orden y el surgimiento de uno nuevo.

Alfredo Ferrero

Universidad Nacional de Córdoba alfredof2912@gmail.com

Para citar esta reseña:

Ferrero, A. (2019): “Caula, E. (2014). Mercaderes de mar y tierra. Negocios, familia y poder de los vascos en el Río de la Plata. Rosario: FHUYMAR ediciones. 288 pp." Anuario de la Escuela de Historia Virtual 15, 116-121. 